\title{
ILCEA
}

Revue de l'Institut des langues et cultures

d'Europe, Amérique, Afrique, Asie et Australie

$26 \mid 2016$

Mémoire, vérité et justice en Uruguay

\section{Los difíciles caminos de la justicia en derechos humanos en Uruguay}

Les voies difficiles de la justice en matière de droits de l'homme en Uruguay

The Difficult Paths of Human Rights Justice in Uruguay

\section{Mariana Mota}

\section{CpenEdition}

\section{Journals}

Edición electrónica

URL: http://journals.openedition.org/ilcea/3897

DOI: $10.4000 /$ ilcea.3897

ISSN: 2101-0609

Editor

UGA Éditions/Université Grenoble Alpes

Edición impresa

ISBN: 978-2-84310-334-6

ISSN: $1639-6073$

Referencia electrónica

Mariana Mota, "Los difíciles caminos de la justicia en derechos humanos en Uruguay », ILCEA [En línea], 26 | 2016, Publicado el 07 julio 2016, consultado el 20 abril 2019. URL : http:// journals.openedition.org/ilcea/3897 ; DOI : 10.4000/ilcea.3897

Este documento fue generado automáticamente el 20 abril 2019.

(c) ILCEA 


\title{
Los difíciles caminos de la justicia en derechos humanos en Uruguay
}

\author{
Les voies difficiles de la justice en matière de droits de l'homme en Uruguay \\ The Difficult Paths of Human Rights Justice in Uruguay
}

\section{Mariana Mota}

\section{La Justicia Transicional}

1 La Justicia de Transición tiene como objeto el abordaje de crímenes ocurridos en una sociedad que ha vivido procesos de conflictos armados, de abusos de poder institucional, de imposición autoritaria de un régimen político, $u$ otros procesos similares que se caracterizan por la ocurrencia de graves y generalizadas violaciones a los derechos humanos.

Dada la dimensión de los delitos en examen (con características tales como la de haberse cometido en forma masiva, contra cierto grupo de personas, practicados por agentes del Estado o particulares con tolerancia de éste, vinculado generalmente a motivos ideológicos, etc.), la Justicia Transicional no solo reclama la acción de la justicia, en su cometido de tramitar los juicios que se le planteen, sino que interesa, para alcanzar sus objetivos, la intervención de otras disciplinas, como la sociología, la psicología, la antropología, la historia, etc. Asimismo, la Justicia Transicional requiere, para poder transitar hacia las metas propuestas, del accionar de otros órganos, estatales o particulares, diversos a los de la administración de justicia, actuando en igual sentido al propuesto.

3 Los logros que se alcancen con la Justicia Transicional trascienden a la o las víctimas individualmente consideradas para involucrar también a la sociedad como otra víctima de las graves violaciones ocurridas en el período histórico a analizar. Por ende, la importancia de la Justicia Transicional excede el juicio individual para interesar a todos los individuos. 
Siendo entonces tal la amplitud de las áreas a abordar por la Justicia Transicional, así como la participación de otros organismos no jurídicos que se vinculan de diversa manera, los objetivos o metas trazados pueden variar según la sociedad en que este proceso se instale. Esto lleva a que se formulen diferentes conceptos de Justicia Transicional conforme el contenido que se le dé y los resultados que se busquen con ella. Analizar entonces lo que se ha hecho en un lugar determinado en el tema requiere partir previamente de una definición de Justicia Transicional.

5 La investigadora Francesca Lessa, en su libro ¿Justicia o impunidad? donde investiga los avances y obstáculos que, en la materia, se han llevado adelante en Uruguay, toma como punto de partida el concepto de Justicia Transicional que realiza el Secretario General de la ONU de 2004. Éste la define como toda aquella variedad de procesos y mecanismos asociados con los intentos de una sociedad por resolver los problemas derivados de un pasado de abusos a gran escala, a fin de que los responsables rindan cuentas de sus actos, servir a la justicia y lograr la reconciliación. Tales mecanismos pueden ser judiciales o extrajudiciales y tener distintos niveles de participación internacional (o carecer por completo de ella) así como abarcar el enjuiciamiento de personas, el resarcimiento, la búsqueda de la verdad, la reforma institucional, la investigación de antecedentes, la remoción del cargo o combinaciones de todos ellos (UNSC, 2004: 4, § 8).

6 Una definición lo suficientemente amplia como para abarcar las diversas modalidades de Justicia Transicional que se pretenda.

7 Adentrándonos en dicha definición y específicamente en los mecanismos judiciales, partimos de considerar, conforme lo expresa Kai Ambos, que las víctimas tienen derecho: a) a la verdad, que no se limita al derecho individual sino, como se señalará, se trata también de un derecho de carácter colectivo de la sociedad de saber lo que le ocurrió a su tejido social; b) a la justicia, esto es, a un sistema de justicia que le permita acceder a un juicio justo, efectivo, rápido que permita individualizar a los responsables y que se les apliquen sanciones; c) la reparación o lo que permita a la víctima volver a empoderarse de sus derechos (Ambos, Malarino \& Elsner, 2009).

Entendemos por mecanismos judiciales no solamente la tramitación del proceso sino que reclama de la administración de justicia una acción que, a la vez que se dirija a la determinación y sanción de los responsables, se verifique en forma tal que sea reparadora de la víctima y que contribuya en la construcción del relato histórico de la sociedad a través de los hechos y circunstancias vividos por la víctima.

9 La actuación de la justicia tendrá entonces incidencia en las demás medidas que pueden integrar esa amplia definición antes referida, de ahí que es importante considerar cómo se realiza y cuáles son sus resultados.

\section{Mecanismos jurídicos aplicados en Uruguay}

En Uruguay, el abordaje de los crímenes ocurridos bajo el terrorismo de Estado ha sufrido avances y retrocesos. De inmediato al restablecimiento de los mecanismos democráticos al término de la dictadura, las denuncias radicadas de numerosas violaciones a los derechos humanos reclamaban una actuación del sistema judicial acorde a las graves demandas planteadas. Estas denuncias abarcaron una selección de los crímenes ocurridos, excluyéndose muchas otras modalidades de avasallamiento de derechos. Por ejemplo, no se formuló ninguna denuncia de las numerosísimas violencias sexuales sufridas, tampoco 
se denunció la tortura siendo que constituyó un mecanismo sistemático de tratamiento a los detenidos y presos, se omitió asimismo toda referencia a la vulneración de los derechos económicos sociales y culturales que sufrió masivamente toda la sociedad (no hay denuncias sobre persecuciones laborales, destituciones, exilios forzados, etc.). Por razones que no resultan claras se priorizó la denuncia de las más graves violaciones: homicidios, desapariciones, secuestro de niños, descontextualizando tales crímenes del escenario de abusos masivos y gravísimos a los derechos humanos en que se verificaron y que graduaba, en forma aun mayor, el terrorismo de Estado en que fueron cometidos ${ }^{1}$.

11 Si bien es cierto que muchas víctimas precisaron un cierto tiempo para poder exteriorizar tanto horror sufrido (aún hay quienes demuestran su imposibilidad de verbalizarlo), esta selección de los delitos denunciados no fue resultado exclusivo de esa paralización individual de accionar contra los represores sino que fue una opción consciente y deliberada de quienes formularon las denuncias (en su mayor parte organismos de derechos humanos). Esto marca desde el inicio una limitación de las víctimas al derecho de justicia y al derecho de saber la verdad que, con el correr de los años, ha reportado perjudiciales consecuencias tanto en relación a la pretendida Justicia Transicional como en otros aspectos estrechamente vinculados como, por ejemplo, la memoria de ese pasado reciente.

Pero aun en ese inicial y selectivo grupo de denuncias, el camino hacia la justicia se transitó por breve lapso porque la ley de caducidad ${ }^{2}$ puso punto final (o pretendía que fuera punto final) al progreso de los juicios y con ello al conocimiento de lo ocurrido y sanción a los responsables.

13 El largo tiempo de inacción, que impidió toda actuación judicial significativa, obstaculizó, además, cualquier análisis de qué justicia pretendía llevarse adelante en Uruguay e incluso, si efectivamente se pensaba en una Justicia de Transición o, simplemente, se pretendía la tramitación de estas causas judiciales sin ninguna otra consideración ni diferencia con las que componen el quehacer diario de cualquier juzgado en tiempos de normalidad institucional ${ }^{3}$.

Esta diferencia implica excluir la serie de contenidos que tienen los mecanismos de justicia en la referida Justicia Transicional para las víctimas y para la sociedad en ese derecho colectivo a saber.

Luego de treinta años de finalizada la dictadura y a diez años desde que la ley de caducidad dejó de significar un obstáculo insalvable, como sin duda lo representaba en los años anteriores, se puede concluir que el proceso que ha transitado y recorre actualmente Uruguay no es, ni pretende serlo, en procura de aspectos que hacen a una Justicia Transicional, sino que se ha dirigido a tratar estos delitos dentro del universo de delitos comunes como los que diariamente llegan a los juzgados. Esto deriva en consecuencias que intentaremos analizar.

16 A diferencia de otros países de la región que llevaron adelante procesos de enjuiciamiento por los crímenes ocurridos en las dictaduras sufridas, de similares características que la uruguaya, en Uruguay no se constituyeron tribunales judiciales específicos para el tema, no se asignaron a algunos juzgados competencia exclusiva para tramitar estos juicios y ni siquiera se instruyó a los jueces penales a fin de considerar los aspectos especiales que tales procesos iban a presentar dadas las características excepcionales de los hechos denunciados. 
17 Por el contrario, se pugnó durante todo este tiempo para que las denuncias relativas a los crímenes cometidos durante el terrorismo de Estado se tramitaran como si se tratara de una denuncia de un delito común.

Varias son las características que impedían e impiden que estos delitos se aborden de esta manera.

Si bien la justicia busca alcanzar la verdad de lo ocurrido y aplicar las sanciones que sean pertinentes, en el abordaje de una Justicia de Transición el objetivo va mucho más allá de estos resultados. Como se señalaba anteriormente, interesa también satisfacer el derecho a conocer la verdad del cual también es titular la sociedad. Importa asimismo la búsqueda de la reparación de la víctima y sin lugar a dudas las garantías de no repetición constituyen un objetivo bien importante en estos procesos, elementos claves de este tipo de justicia que no necesariamente son esenciales en la justicia ordinaria que solo pretende la determinación del responsable para aplicarle la sanción prevista en la norma penal.

20 En ese sentido, la aplicación de un proceso penal que no tiene en cuenta estos objetivos omite también considerar la participación de la víctima. El actual ordenamiento jurídico, en la Ley $n .^{\circ} 18.026$-art. 13- permite a la víctima, en un proceso penal, presenciar audiencias y el diligenciamiento de la prueba además de poder aportar elementos probatorios a la causa. Tal normativa solo es aplicable, actualmente, en relación a los juicios por delitos de lesa humanidad. Por lo tanto, excluir la calificación de tal carácter a los delitos cometidos durante el terrorismo de Estado implica, procesalmente, impedir que la víctima tenga una participación activa en el proceso. Ello va más allá de la posibilidad cierta de presentar prueba o de presenciar interrogatorios, inspecciones oculares, careos, etc., también elude la significación que tiene para las víctimas de estos crímenes transitar estos procesos e intervenir en ellos contribuyendo a su reparación integral ${ }^{4}$.

21 Tampoco se ha tenido presente la calidad de tales víctimas al momento de ser citadas y de recibir sus declaraciones ${ }^{5}$. No se ha instituido equipos de acompañamiento o de asistencia para evitar la re victimización ineludible que ocurre al volver a recordar los hechos profundamente traumáticos que las han convertido irreversiblemente en víctimas.

22 Relacionado con lo anterior, las concurrencias a los lugares que fueron centros de detención como parte de prueba dispuesta por las sedes judiciales no consideran el impacto que esta actuación conlleva en las víctimas para lo cual deberían ser asistidas e informadas de las condiciones en que se realizará la prueba, pero tampoco se les ampara en el derecho a concurrir olvidando que ello constituye también una forma de reparación ${ }^{6}$

23 Todas estas observaciones determinan que la actuación judicial en forma alguna consideró -ni considera actualmente- las especiales características de estos delitos lo que se confirma con las resoluciones judiciales las que, en un porcentaje abrumador, excluyen la calificación de tales ilícitos como delitos de lesa humanidad. Por otra parte se elude la consideración del contexto histórico en que se verificaron los crímenes al momento de analizar la responsabilidad de los autores en el marco del terrorismo de Estado ${ }^{7}$.

24 Finalmente, la calificación de tales delitos como comunes permite la aplicación de institutos como los de prescripción que determina la clausura de causas ${ }^{8}$. Luego, los que han sido encarcelados, tengan o no condena, pueden beneficiarse con la prisión 
domiciliaria, extremo que está expresamente excluido para quienes han sido enjuiciados por delitos de lesa humanidad, calidad que no les ha sido atribuida?.

Los enjuiciamientos de los crímenes cometidos en el terrorismo de Estado, de tramitarse conforme los objetivos de una Justicia Transicional, requerirían además que fueran públicos, contemplando así el derecho a saber de la sociedad. En su lugar, de las causas actualmente en trámite y también de las que ya finalizaron, solo se conoce un sintético resumen, de una extensión mayor o menor según quien redacte la nota periodística. Sin excepción, en ninguno de estos procesos se ha dado a conocer los elementos que llevaron al enjuiciamiento, el contexto en que ocurrieron, las acciones que llevaron adelante los responsables, la actuación u omisión de las autoridades de la época, etc.

Se asiste en los relatos de prensa con justificada indignación a un relato pormenorizado de un delito común, de los que corrientemente acontece en cualquier sociedad, mientras que estos casos, que cobraron vidas por medios aberrantes, que hostigaron por años a detenidos imprimiéndoles traumas permanentes, que rebajaron la dignidad humana de tantas personas, son apenas un dato en la prensa mayoritaria y de muy poco análisis en los centros educativos en sus diversos grados.

Finalmente, se ha excluido toda investigación sobre ilícitos económicos ocurridos en la dictadura y cometidos por agentes del Estado en perjuicio de particulares. Tampoco se ha procurado determinar la responsabilidad de civiles en la comisión de los delitos analizados circunscribiéndose el campo investigativo a los militares individualizados en cada causa.

\section{La participación de otros organismos estatales}

Se señalaba al inicio que la investigación de crímenes perpetrados por agentes del Estado reclama en forma especial la participación de otros organismos diversos al Poder Judicial. Sin embargo, en Uruguay, la búsqueda de la verdad y la procuración de la justicia ha quedado en manos del Poder Judicial en forma exclusiva, desarrollándose en la forma antes expresada, excluyente de los objetivos previstos en la Justicia Transicional.

El Estado ha permanecido ausente en todas estas actividades, soslayándolo en la agenda de gobierno y tratándolo como un problema que interesa solo a un colectivo: el de las víctimas o sus familiares, y en relación a algunos militares, quienes son sindicados como los únicos responsables. Las Administraciones han considerado que los reclamos de verdad y justicia corresponde sean examinados y resueltos exclusivamente en la órbita jurídica, bajo la forma de litigio - de ahí la atribución exclusiva del tema al Poder Judicial. En suma, se representa a los crímenes del terrorismo de Estado exclusivamente como material de competencia judicial donde dos partes dirimen sus contiendas, en un ámbito privado, del que la sociedad es mera espectadora.

31 En algunos momentos, las diversas administraciones gubernamentales han abordado estos reclamos de forma puntual, en respuesta a la presión de los grupos de interés cesando la intervención al momento de brindar lo que se considera la solución adecuada (conformación de comisiones investigadoras, sanciones de leyes de reparación económica, consagración de algún lugar como sitio de memoria). No obstante, en la construcción de políticas públicas no se ha tenido presente las consecuencias que la dictadura imprimió en cada uno de los derechos que fueron vulnerados, incluidos los derechos a la verdad y la justicia. No se ha hecho hincapié en la reforma institucional de 
algunos organismos ni se ha revisado su funcionamiento, lo que podría constituir algunas de las garantías de no repetición inmersas en la justicia transicional, que se evidencian como necesarias.

Pasando por alto los gobiernos que van desde los años 1985 a 2000 (períodos de gobiernos de Partido Colorado y Partido Nacional) donde absolutamente nada se hizo por el tema dado que aplicaron consecuentemente la ley de caducidad y obstaron toda actividad investigativa, la constituida Comisión para la Paz, en el gobierno de Batlle, se abocó a dar una respuesta a los delitos más graves excluyendo toda referencia a las demás violaciones de los derechos humanos y restringiendo, por consiguiente, a un importante grupo de víctimas, el conocimiento de lo ocurrido. Finalizadas las actividades de la Comisión, y aun sin tener en cuenta la falsedad de la mayor parte de sus conclusiones (lo que pudo verificarse mucho tiempo después), el Estado volvió a quedar al margen de este proceso demostrando que se trataba de un tema que no interesaba en la agenda de gobierno ni se consideraba que fuera relevante más que para un limitado grupo de personas.

Posteriormente, los gobiernos del Frente Amplio, si bien permitieron un avance significativo con relación a la falta absoluta de actividad anterior, siguieron considerando que solo correspondía al Poder Judicial atender el reclamo de verdad y justicia, demanda que se sigue atribuyendo a un sector minoritario de la población.

No puede entenderse que la conformación de la Secretaría de Seguimiento de la Comisión para la Paz sea la necesaria actitud pro activa, que tenía y tiene que adoptar el Estado, puesto que dicho organismo tuvo una actuación muy residual y por momentos incluso obstaculizadora de la búsqueda de la verdad (con excepción de técnicos y profesionales que integraban el equipo que tuvieron destacada actuación en el avance de los propósitos de la Comisión).

Luego, y ya en este período de gobierno, se vuelve a repetir el mismo esquema: un organismo se ocupará de los problemas aun no resueltos del pasado reciente. Además de la Secretaría de Derechos Humanos para el pasado reciente (ex Secretaría de Seguimiento de la Comisión para la Paz), se constituyó el Grupo por Verdad y Justicia con amplísimos cometidos y con una integración muy diversa. Al igual que en períodos anteriores, estas comisiones, grupos, organismos designados, tienen un funcionamiento generalmente reservado, hacia adentro, mostrando pocas veces los resultados y con poca o nula coordinación con otros actores (personas o colectivos) que también trabajan en el tema. Este grupo comenzó a funcionar en mayo del pasado año 2015, hasta el momento de escribir este artículo, no ha reportado los avances que ha realizado ni informó de las actividades que viene desempeñando.

Sin duda que es necesario la conformación de grupos de trabajo y fundamental que el Estado se involucre en su financiamiento, pero todo esto no es suficiente. Es necesario que el Estado, a través de sus diversos organismos promueva las coordinaciones entre los diversos órganos que se encuentran abocados a esta tarea, se requiere transversalizar la información que se maneja en esos diversos ámbitos alejándose del secretismo que generalmente envuelve a los trabajos en comisiones $\mathrm{y}$, principalmente, promoviendo constantemente la participación de todos aquellos que se interesen por el objetivo trazado. Estas tareas deberían impulsarse desde los organismos de dirección del Estado, involucrándose en sus progresos, comprometiéndose activamente en la solución de los obstáculos y difundiendo sus resultados ya no como un logro de un grupo de personas sino como una conquista del Estado en su conjunto en la lucha contra la impunidad y en 
el logro de los objetivos de una Justicia Transicional en los términos referidos al comienzo.

La difusión de los avances y los objetivos trazados son necesarios además para que la sociedad conozca más sobre ese pasado reciente del que solo se ha expresado una historia parcial, sostenida por la teoría de los dos demonios donde solo son protagonistas algunos integrantes de esa sociedad y quienes pretenden dirimir sus atribuidas rivalidades de una forma que no contempla en absoluto a las demás víctimas ${ }^{10}$.

En este relato de la historia, las nuevas generaciones no se consideran partícipes y observan los hechos de la dictadura como ocurridos en un pasado remoto carente de vinculación con los problemas del presente y sin relación con el futuro del que estos jóvenes integrantes son y serán sus protagonistas activos.

39 Del mismo modo, los procesos judiciales se visualizan como una pérdida de tiempo, en tanto se investigan hechos que ocurrieron hace mucho tiempo, de los que no se conocen las circunstancias y se considera que su judicialización no es útil para tratar las actuales formas de delincuencia.

40 Esta desconexión entre un pasado cercano violento y avasallador de los derechos y un presente que no investiga lo ocurrido no garantiza la no repetición de tales vulneraciones, siendo ello un cometido esencial en una Justicia de Transición.

\section{Conclusiones}

41 El panorama descripto lleva a concluir que los derechos a la verdad y la justicia reclamados por las víctimas y grupos sociales comprometidos con tales postulados han sido largo tiempo eludidos por los diversos órganos del estado, posteriormente abordados en forma tangencial y actualmente transitan una etapa que, en apariencia, conduce a la realización de dichos derechos pero, ciertamente, se encuentran obstaculizados por diversos factores que, de no resolverse, terminarán por hacer imposible los objetivos más básicos de la justicia.

42 Las causas judiciales son varias veces paralizadas por reiterados recursos procesales que instalan los indagados y el sistema judicial no ha sabido compatibilizar las garantías judiciales con el deber de brindar una justicia sencilla, rápida y efectiva conforme lo dispone la Declaración Americana de los Derechos y Deberes del Hombre en su art. 18, la Convención Americana en su art. 25 y la sentencia de condena a Uruguay en el caso Gelman ${ }^{11}$.

43 No se ha procurado una formación jurídica de los diversos operadores de justicia que permita superar la discusión acerca de la calificación jurídica de los delitos investigados (la que ya ha sido largamente superada en otros países de la región), y tampoco se realiza una adecuada valoración de la prueba conforme las características de los crímenes en examen ${ }^{12}$.

44 Siguen siendo las víctimas, en forma absolutamente exclusiva, quienes formulan las denuncias, buscan la prueba y la aportan a la causa. Debería ser el Estado quien asumiera el rol de denunciar, a través de sus fiscales nacionales, los crímenes cometidos durante el terrorismo de Estado. Correspondería además que tuviera una actitud pro activa para la búsqueda y puesta a disposición de los archivos aun ocultos. Finalmente, debería también 
asumir la asistencia técnica a las víctimas y brindar protección a los testigos en estos procesos judiciales.

La extrema lentitud con que tramitan las causas, obedeciendo a la estrategia planteada por los abogados de los indagados, aunado a la discusión todavía no superada de la calidad de los delitos en examen pone en serio riesgo que se pueda avanzar sustancialmente en la determinación de responsables y su enjuiciamiento pero además impide construir, desde la verdad forense, una historia común a todos los uruguayos que resulta necesaria para adoptar las medidas necesarias a fin de evitar la repetición de períodos caracterizados por masivas vulneraciones a los derechos humanos.

«Nada se parece tanto a la injusticia como la justicia tardía» (Seneca). No puede perderse de vista que el derecho a la justicia es un derecho humano y es deber del Estado proteger y garantizar su ejercicio. En tanto las graves violaciones a los derechos humanos ocurridas durante la dictadura permanezcan sin ser investigadas y sus responsables no sean sancionados, estamos sin duda ante el incumplimiento del Estado, hecho que debe señalarse y al cual debe exigirse la correspondiente actuación.

\section{BIBLIOGRAFÍA}

Ambos Kai, MALARIno Ezequiel \& ElSNER Gisela (eds.) (2009), Justicia de transición: informes de América Latina, Alemania, Italia y España, Montevideo: Fundación Konrad Adenauer, Oficina Uruguay, <www.kas.de/wf/doc/kas_18236-544-4-30.pdf>.

LESSA Francesca (2014), ¿Justicia o impunidad? Cuentas pendientes en el Uruguay post-dictadura, Montevideo: Debate.

United NATions Security Council, The Rule of Law and Transitional Justice in Conflict and Post-Conflict Societies: Report of the Secretary-General, 23 de agosto de 2004, S/2004/616, <www.refworld.org/ docid/45069c434.html>.

\section{NOTAS}

1. La primera denuncia por violaciones sexuales se radicó por un grupo de mujeres en el año 2011. Del año 2010 data la primera denuncia por torturas de un grupo de ex presos políticos respecto del lugar donde sufrieron detención, en la base aérea Boizo Lanza. A la fecha no se han formulado denuncias por las detenciones arbitrarias, persecuciones políticas, exilios forzados.

2. Ley $n .^{\circ} 15.848$ llamada «ley de caducidad de la pretensión punitiva del Estado», sancionada en 1986.

3. La jurisprudencia y la doctrina recién comienzan a debatir acerca de la calificación de tales delitos como de lesa humanidad a partir del año 2011, aproximadamente, discusión que se extiende aun hoy. Este proceso de análisis jurídico de la normativa aplicable se verificó en los otros países de la región muchos años antes, al considerarse su aplicación en los juicios que se llevaban adelante (Chile, Argentina). En estos sistemas jurídicos ya no es posible discutir la 
calificación de lesa humanidad, permitiendo el progreso de los juicios en tiempos acordes a lo esperado.

4. El proceso penal en Uruguay se encuentra en tiempos de cambio. El nuevo sistema prevé la participación de la víctima para todo tipo de proceso sin depender de la calidad del delito investigado. Esta participación consagrada es sin embargo limitada - lo que ha sido observado por organismos internacionales- y la reforma que la ha instituido todavía no se encuentra vigente.

5. La inevitable revictimización que se produce al convocar a las víctimas al proceso reclama, en estos casos de delitos de extrema gravedad, un especial cuidado en las formas adoptadas para las citaciones, eludiendo dentro de lo posible la intervención de organismos que otrora estuvieron vinculados a la represión (policía, fuerzas armadas), apelando a otras formas de convocatorias. De igual manera en la forma en que se lleva adelante la recepción de sus declaraciones por el sistema judicial y en las diversas instancias del proceso.

6. Esta concurrencia a los lugares donde se produjeron las violaciones a los derechos no ha sido priorizando los intereses de las víctimas. En el pasado año 2015 se dispuso judicialmente la visita a una unidad militar (Servicio de Material y Armamento), donde funcionaba un centro de detención y torturas conocido como «Infierno Grande» o «300 carlos». La sede judicial donde se lleva el juicio por torturas denunciadas por numerosos ex presos limitó el ingreso a algunos denunciantes que querían ver el lugar donde fueron detenidos y agredidos. Esta limitación es totalmente arbitraria y va en sentido contrario a la rehabilitación. Debe tenerse presente que la presencia en un ex centro de torturas en calidad de denunciante tiene un profundo contenido reparador en relación a aquella condición en la que permanecieron en ese lugar, como víctimas.

7. Recientemente, la absolución de quien fuera uno de los agentes de detención del maestro Julio Castro, desaparecido en agosto de 1977, fue confirmada en la instancia tramitada ante la Suprema Corte de Justicia. Tanto la sentencia que lo absuelve y dispone su libertad como posteriormente la sentencia de la Corte que la confirma, omiten absolutamente analizar el hecho en el contexto histórico en que se verificó, en una dictadura que, en ese entonces, llevaba cuatro años y ya se caracterizaba por sus masivas detenciones, numerosas muertes y desapariciones forzadas, todos delitos cometidos por agentes del Estado o por particulares con aquiescencia del Estado.

8. Se han archivado causas donde se investigaban delitos cometidos en la época de la dictadura, aplicando el instituto de la prescripción.

9. En el cierre del año 2015, a los represores Gavazzo, Rama y Bardesio, se les concedió la prisión domiciliaria, según indició el juez que les concedió el beneficio, fue fundado en «razones humanitarias» [sic]. Tal concesión no es posible, conforme al art. 9 inc. $2 .^{\circ}$ n. ${ }^{\circ} 3$ de Ley n. ${ }^{\circ} 17.897$, cuando se les ha condenado por delitos de lesa humanidad lo que, en el caso no se verificaba pues la condena de los dos primeros nombrados fue por veintiocho homicidios (aunque se trató de desapariciones forzadas, calificación que peticionó la fiscalía actuante en todas las instancias), excluyéndoles la calidad de delitos de lesa humanidad.

10. En línea con esa teoría, parte de la dirigencia del MLN, algunos de cuyos integrantes ejercieron cargos de dirección en la anterior administración, ha propuesto liberar a los enjuiciados por crímenes cometidos en la pasada dictadura. No se ha interesado por la tramitación de otros juicios entendiendo la lógica de combatientes, donde se justifica, en un enfrentamiento, abusos de derechos en cada bando.

Por su parte, los militares implicados en estas violaciones $-\mathrm{y}$ varios políticos que coinciden en la misma línea de pensamiento- consideran, en similar sentido, que se dieron abusos o errores enmarcados en una situación de guerra y, por ende, no son pasibles de enjuiciamiento.

11. El caso Perrini es solo un ejemplo de esta lentitud impuesta por la estrategia de la defensa de los indagados, siendo que los elementos probatorios se habían reunido en junio de 2012 y la causa estaba en estado de decidir sobre las responsabilidades atribuidas por el Ministerio Público 
debieron transcurrir tres años para que finalmente se resolviera el enjuiciamiento ya no de los cuatro indagados sino solo de uno de ellos, los demás, en el lapso transcurrido, fallecieron.

12. En reciente sentencia (agosto de 2015), la Suprema Corte de Justicia, con una integración diversa por la incorporación de otro integrante en sustitución de uno saliente, ha admitido la calidad de delitos de lesa humanidad a los atribuidos en una causa, carácter que fue negado en anteriores pronunciamientos del mismo órgano y en la mayoría de los tribunales de apelaciones así como en casi la totalidad de los juzgados de primera instancia.

\section{RESÚMENES}

A partir de un breve resumen de las funciones y mecanismos de la Justicia Transicional, se propone analizar la experiencia uruguaya en materia de gestión de las graves violaciones a los derechos humanos perpetradas durante el periodo del terrorismo de Estado. A través de observaciones concretas sobre la actuación del Poder Judicial y de otros poderes del Estado en la materia, se demostrará que dicho proceso lejos está de contemplar los cuatro pilares de la Justicia Transicional (verdad, justicia, reparación y garantías de no repetición).

À partir d'un résumé des fonctions et mécanismes de la justice transitionnelle, cet article propose d'analyser l'expérience uruguayenne en matière de gestion des graves violations aux droits de l'homme perpétrées pendant la période du terrorisme d'État. À travers des observations concrètes sur l'action du pouvoir judiciaire et d'autres institutions étatiques en la matière, on verra que ce processus est loin de faire face de manière adéquate aux quatre piliers de la justice transitionnelle (vérité, justice, réparation et garanties de non-répétition).

Starting from a brief overview of the functions and mechanisms of Transitional Justice, we will analyze the Uruguayan experience in managing serious violation of human rights committed during the State terrorism. Through specific remarks on the performance of the judiciary and other branches of the government in the matter, this paper will prove that this process is far from considering the four pillars of transitional justice (truth, justice, reparation and guarantees of non-repetition).

\section{ÍNDICE}

Palabras claves: Justicia Transicional, Uruguay, verdad, justicia, reparación integral, garantías de no repetición

Mots-clés: justice transitionnelle, Uruguay, vérité, justice, réparation intégrale, garanties de non-répétition

Keywords: transitional justice, Uruguay, truth, justice, integral reparation, guarantees of nonrepetition 


\section{AUTOR}

MARIANA MOTA

Jueza, Abogada diplomada de la Facultad de Derecho y Ciencias Sociales de la UdelaR, especialista en Derecho Penal, Derechos Humanos, control de constitucionalidad y jurisdicción universal del Instituto interamericano de Derechos Humanos. 